(2) Open Access Full Text Article

\title{
Improving the quality of psychiatry teaching within the UK undergraduate medical curriculum
}

This article was published in the following Dove Press journal:

Advances in Medical Education and Practice

II March 2016

Number of times this article has been viewed

\section{Sunila J Prasad \\ Pooja Nair \\ Karishma Gadhvi \\ Ishani Barai \\ Mariam Lami \\ Faculty of Medicine, Imperial College London, London, UK}

Correspondence: Sunila J Prasad

Faculty of Medicine, Imperial College, Exhibition Road, London, London SW7 2AZ, UK

Tel +44 20079 47| 7363 ।

Email sunila.prasadII@imperial.ac.uk

\section{Dear editor}

We read with great interest the article by Shah, ${ }^{1}$ which outlines various approaches to increase the exposure of undergraduate medical students to specialties such as psychiatry. While Shah ${ }^{1}$ makes valid suggestions to tackle this issue without altering the undergraduate medical school curriculum, we believe that there is scope for significant improvements within the curriculum for psychiatry in particular.

To initiate this process, the first step may be to acknowledge the intrinsic attitudes of medical students toward psychiatry. Misconceptions among medical students include perceiving psychiatry as emotionally challenging with difficult patients, being taught from an insufficient evidence base, and having a lack of prestige within the medical profession. ${ }^{2}$ The extracurricular exposure to psychiatry proposed by Shah ${ }^{1}$ would mainly target students with a pre-existing interest in psychiatry. In comparison, fundamental changes within the psychiatry curriculum of medical schools may have an impact on a larger proportion of the student body.

Typically, psychiatry is taught in the later years of medical school. However, an early exposure to this vital specialty can be achieved via the integration of psychiatric components into teaching of other specialties. For example, medical students can be encouraged to adopt a more holistic approach during problem-based learning (PBL) sessions by considering the pertinent psychiatric aspects as learning objectives. McParland et $\mathrm{al}^{3}$ compared the effectiveness of PBL with traditional undergraduate psychiatry teaching at University College London and concluded that students showed better academic performance with the PBL course. In this case, although the attitudes of students toward psychiatry remained largely unchanged, the PBL teaching style enabled more effective learning of the subject, which translated into an improved clinical performance and knowledge base. Additionally, teaching of psychiatric conditions could be incorporated into the preclinical neuroscience course in order to explore the scientific basis of psychiatry. With the development of psychiatric neuroscience, residency training programs in the US have also started placing more importance on neuroscience education within psychiatry. ${ }^{4}$ Similar incorporation of psychiatry into neuroscience teaching in medical schools would allow students to appreciate the role of neuroscience in psychiatric practice early in their medical training. Importantly, this may also allow misconceptions about psychiatry to be dispelled early in medical school. Furthermore, Manassis et $\mathrm{al}^{5}$ highlighted that initial interest is a major factor 
influencing the choice of psychiatry as a specialty. Thus, early exposure to psychiatry in medical schools would also enable earlier identification of interested students, who can then be encouraged to pursue psychiatry.

Other novel teaching techniques include the use of popular media such as clips from television programs ${ }^{6}$ to encourage discussion about the widespread presence of mental illness, alongside textbooks to consolidate learning. This was adopted in the development of a seminar program, at the University of Nebraska by McNeilly and Wengel, ${ }^{6}$ utilizing short vignettes from the television program "ER" to effectively demonstrate the practical applications of psychotherapeutic techniques and communication skills to medical students.

Finally, an effective way to enhance the quality of psychiatry placements would be to involve teaching-oriented psychiatrists, without necessarily increasing the length of placements. To support this, a survey conducted among medical students reported that their attitudes toward psychiatry improved with encouragement from senior psychiatrists or if they were particularly inspired by a member of the psychiatric team during clinical attachments. ${ }^{7}$ Hence, practising physicians may be encouraged to reflect upon their impact on the attitudes of students and their future interest in pursuing psychiatry.

We believe these suggestions would ultimately have minimal logistical and financial implications and can be easily incorporated into the curriculum of medical students. As junior doctors, we are highly likely to encounter patients with mental illnesses, as it affects over $25 \%$ of the population. ${ }^{8}$ Therefore, a solid understanding of psychiatry is crucial, regardless of the speciality that we ultimately pursue.

\section{Disclosure}

The authors report no conflicts of interest in this communication.

\section{References}

1. Shah S. Are curriculum changes the ideal method for increasing undergraduate exposure to tomorrow's specialities? Adv Med Educ Pract. 2015;6:153-154.

2. Hadler N, Hadjidemetriou C, Pearson R, et al. Student career choice in psychiatry: findings from $18 \mathrm{UK}$ Medical Schools. Int Rev Psychiatry. 2013;25(4):438-444.

3. McParland M, Noble LM, Livingston G. The effectiveness of problembased learning compared to traditional teaching in undergraduate psychiatry. Med Educ. 2004;38(8):859-867.

4. Roffman JL, Simon AB, Prasad KM, Truman CJ, Morrison J, Ernst CL. Neuroscience in psychiatry training: How much do residents need to know? Am J Psychiatry. 2006;163(5):919-926.

5. Manassis K, Katz M, Lofchy J, Wiesenthal S. Choosing a career in psychiatry: influential factors within a medical school program. Acad Psychiatry. 2006;30(4):325-329.

6. McNeilly DP, Wengel SP. The "ER" seminar. Acad Psychiatry. 2001;25(4): 193-200.

7. McParland M, Noble LM, Livingston G, McManus C. The effect of a psychiatric attachment on students' attitudes to and intention to pursue psychiatry as a career. Med Educ. 2003;37(5):447-454.

8. Dale JT, Bhavsar V, Bhugra D. Undergraduate medical education of Psychiatry in the West. Indian J Psychiatry. 2007;49(3):166-168.

Dove Medical Press encourages responsible, free and frank academic debate. The content of the Advances in Medical Education and Practice 'letters to the editor' section does not necessarily represent the views of Dove Medical Press, its officers, agents, employees, related entities or the Advances in Medical Education and Practice editors. While all reasonable steps have been taken to confirm the content of each letter, Dove Medical Press accepts no liability in respect of the content of any letter, nor is it responsible for the content and accuracy of any letter to the editor.

Advances in Medical Education and Practice

Dovepress

\section{Publish your work in this journal}

Advances in Medical Education and Practice is an international, peerreviewed, open access journal that aims to present and publish research on Medical Education covering medical, dental, nursing and allied health care professional education. The journal covers undergraduate education, postgraduate training and continuing medical education including emerging trends and innovative models linking education, research, and health care services. The manuscript management system is completely online and includes a very quick and fair peer-review system. Visit http://www.dovepress.com/testimonials.php to read real quotes from published authors. 